\title{
A scoping review of the contributions of farmers' organizations to smallholder agriculture
}

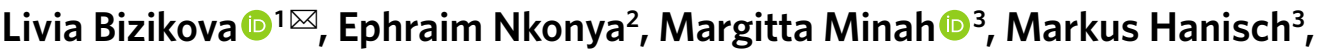 \\ Rama Mohana Rao Turaga $\mathbb{1}^{4}{ }^{4}$, Chinwe Ifejika Speranza $\mathbb{1}^{5}$, Muthumariappan Karthikeyan (1) ${ }^{6}$, \\ Lixia Tang7, Kate Ghezzi-Kopel ${ }^{8}{ }^{8}$, Julie Kelly ${ }^{1}{ }^{9}$, Ashley Casandra Celestin ${ }^{8}$ and Beth Timmers $\mathbb{D}^{10}$
}

\begin{abstract}
Farmers' organizations (FOs), such as associations, cooperatives, self-help and women's groups, are common in developing countries and provide services that are widely viewed as contributing to income and productivity for small-scale producers. Here, we conducted a scoping review of the literature on FO services and their impacts on small-scale producers in sub-Saharan Africa and India. Most reviewed studies (57\%) reported positive FO impacts on farmer income, but much fewer reported positive impacts on crop yield (19\%) and production quality (20\%). Environmental benefits, such as resilience-building and improved water quality and quantity were documented in $\mathbf{2 4 \%}$ of the studies. Our analysis indicates that having access to markets through information, infrastructure, and logistical support at the centre of FO design could help integrate FOs into policy. Natural resource management should also be more widely incorporated in the services provided by FOs to mitigate risks associated with environmental degradation and climate change. Finally, farmers who are already marginalized because of poor education, land access, social status and market accessibility may require additional support systems to improve their capacities, skills and resources before they are able to benefit from FO membership.
\end{abstract}

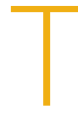

he adoption of the United Nations Sustainable Development Goals (SDGs) in 2015 signalled a global commitment to combat hunger and improve the well-being of small-scale producers and the environment. Small-scale producers contribute substantially to the food supply ${ }^{1-3}$, yet many experience food insecurity ${ }^{4}$. They are also highly vulnerable to climate change and environmental degradation ${ }^{5}$ with particular severity in sub-Saharan Africa (SSA) and South and East Asia 6

Farmer organizations (FOs) such as associations, cooperatives, producer organizations, self-help and women's groups, are collective institutions intended to support members' interests ${ }^{7,8}$. FOs may help small-scale producers access markets, credit and rural extension services ${ }^{9,10}$ as well as manage shared natural resources ${ }^{11}$. FOs can build farmer skills in production, marketing and leadership and strengthen psychological well-being ${ }^{12}$. Building on these contributions to farmers, FOs have become core elements of rural development, agricultural productivity and anti-poverty policiesespecially in Africa and South Asia ${ }^{13,14}$.

Questions have arisen about the equity of FOs, including whether they serve mainly middle-class farmers, rather than the poorest and most vulnerable farmers ${ }^{15,16}$. In some contexts, FO benefits have been shown to vary depending on the crops grown, farmers' access to resources and membership heterogeneity ${ }^{14,17}$. Experience from Kenya, Ethiopia and South Africa also indicates that FOs often depend on support from governments and other agencies $^{18,19}$ and that the benefits of FOs to individual members can be limited by production volumes, infrastructure challenges and inadequate banking services, as well as limited managerial and leadership skills ${ }^{16,20}$.
More evidence on the impact of FOs is urgently needed for governments and donor organizations to identify effective interventions to achieve the SDGs, including target 2.1 to fight hunger, 2.3 to improve the income of smallholders and 2.4 to promote environmentally friendly agricultural practices and responses to climate change. Although several studies have reviewed the contributions of FOs towards those objectives, most have focused on a subset of FO types and/ or individual countries ${ }^{12,21,22}$. Many have not applied a systematic approach ${ }^{23}$.

Here we explore the contributions of FO membership by reviewing the scientific literature on the impacts of FOs on small-scale producers in SSA and India-both of which have a long tradition of cooperatives and other $\mathrm{FOs}^{24,25}$. More specifically, we analyse the findings of 239 studies to elicit the contributions of FOs to income, empowerment, agricultural production, food security and the environment. Details of the literature screening and eligibility criteria can be found in the Methods and in Box 1 .

\section{Results}

Overview of the included studies. The 239 studies included in this scoping review document FOs in 24 countries (Fig. 1). All studies were published between 2000 and 2019 , most (192, or $80 \%$ of the total) since 2010 . The majority used quantitative methodologies (53\%) and involved at least 100 respondents (64\%).

The reviewed studies included seven types of FOs (Fig. 2b): agricultural cooperatives, farmer associations and groups, rural self-help groups and women's groups, dairy cooperatives, producer groups, natural resource management groups and rural financial cooperatives.

IInternational Institute for Sustainable Development, Ottawa, Ontario, Canada. ${ }^{2}$ International Food Policy Research Institute, Washington, DC, USA ${ }^{3}$ Department of Agricultural Economics, Faculty of Life Sciences, Humboldt-Universität zu Berlin, Berlin, Germany. ${ }^{4}$ Public Systems Group, Indian Institute of Management Ahmedabad, Ahmedabad, India. ${ }^{5}$ Institute of Geography, University of Bern, Bern, Switzerland. ${ }^{6}$ Department of Cooperatives, College of Business and Economics, Wollo University, Dessie, Ethiopia. ${ }^{7}$ China Agricultural University, Beijing, China. ${ }^{8}$ Cornell University, Ithaca, NY, USA. ${ }^{9}$ University of Minnesota, Minneapolis, MN, USA. ${ }^{10}$ International Institute for Sustainable Development, Winnipeg, Manitoba, Canada. ${ }^{\circledR}$ e-mail: Ibizikova@iisd.ca 


\section{Box 1 | Key definitions for the identification of relevant studies}

Small-scale producers. Rural producers that meet at least two of the four following criteria: land size, labour availability (especially family members), market orientation (that is, whether production is for personal consumption or sale/barter in markets) and economic size.

Farmer organization. Formal or informal membership-based, collective action institution with the purpose of assembling and possessing established organizational structure to support members in pursuing their individual and collective interests. One essential function is to organize relations with the external world to mediate between members and others who act in their economic, institutional and political environment. This definition includes farmers' associations, farmer cooperatives, farmer clubs, farmer groups, producer organizations and women's groups.

FO services. Actions, strategies or activities undertaken by FOs to help small-scale producers/smallholder farmers generate more income and have better access to food and other raw materials. Typical examples are agricultural extension, education, training and other ways to work with or for farmers.

Environmental impacts. Positive or negative impacts of FO services on the environment. Positive impacts may include improved water quality, greater water availability, reduced erosion, reduced pollution, greater use of renewable energy, greater climate change resilience and lower vulnerability. Negative impacts could include water, soil and air pollution, deforestation and so on

Livelihood impacts. Changes to the capabilities, assets (stores, resources, claims and access) and activities required for living.

Sustainable livelihood. A livelihood that can cope with and recover from stresses and shocks, maintain or enhance its capabilities and assets, and provide livelihood opportunities for the next generation; it also contributes net benefits to other livelihoods at the local and global levels and in the short and long terms. In this scoping review, income and food security are the two most important components for measuring impacts on livelihoods.

We characterized the studies by FO membership and crop type, where relevant. Out of 228 studies that provided data on membership, 171 studies (75\%) involved FOs with open membership, unrestricted by gender, age or any other qualification. The other studies $(25 \%)$ had exclusively or mostly women members (Supplementary Fig. 1.3).

Of the 238 studies that provided data on type of production, more than half $(132$, or $55 \%$ of the total) focused on crop production alone and included FOs working with cereals, vegetables, coffee and fruits; $24 \%$ (56 studies) focused on livestock only, and $21 \%$ (51 studies) focused on both crop and livestock production (Supplementary Figure 1.3). Agricultural cooperatives and farmers' associations had the strongest focus on crop production $(73 \%$ and $68 \%$ respectively). We found only limited information on other FO characteristics, such as membership costs (found for 37 studies, 15\%) (Supplementary Fig. 1.4).

FO services for members. The services FOs provided to their members can be grouped into 11 categories (Fig. 2), of which the most common (129 studies, 54\%) was 'marketing services to increase product sales' (such as connecting to specific markets to sell products, shared transport or storage of the products and the establishment of contacts between FO members and buyers). The second most common category was 'providing access to market information' on product prices and trends, seasonality and regional changes (111 studies, 46\%). The third most common was 'extension and educational services', which both promote improved production and marketing practices, as well as build financial literacy (89 studies, 37\%). The first and third categories were widely represented regardless of the type of FO or membership. Other services, such as linking farmers to external programmes, infrastructure development/management and policy advocacy with local/sub-national governments, were also found in some FOs, but their frequency in the reviewed studies is low.

Most studies described FOs that provided multiple services, but 25 of the studies (4\%) focused on FOs that solely provided financial services, including financial cooperatives and rural self-help and women's groups. FOs offering multiple services typically addressed output marketing, market information and extension services and were analysed by $32 \%$ of the studies. They were mostly agricultural or dairy cooperatives, farmer associations and groups. Studies focused on the FOs from India show that rural self-help groups and women's groups tended to deliver financial, extension and education services such as certification and improved production practices, financial literacy, marketing skills and skills for income generation, strengthening members' access to income, savings, credit and empowerment.

FO membership impacts. The observed FO impacts could be grouped into six categories: income, yield, production quality, environment, empowerment and food security (Fig. 3a). Of the 239 studies, $98(41 \%)$ focused on a single measurable impact (that is 'improved' or 'not improved') in response to FO membership.

Sixty-seven per cent of the studies (161) reported only cases of improvement (in one or more impact categories) associated with FO membership; $21 \%$ (50) reported both cases of improvements and cases of non-improvements (in one or more impact categories). Finally, $12 \%$ of studies (28) reported only cases of no measurable improvement (in one or more of the impact categories studied).

Income. Changes in income are the most investigated impact, included in 174 studies (73\%). Of the 239 studies, 58\% identified positive impacts on income and only $15 \%$ saw no improvements at all. These income improvements were mostly delivered by FOs engaged in crop production (55\%) and with no restriction on membership (67\%) (Fig. 3b). The proportion of studies that reported improvement in incomes is similar across FO types (Fig. 3c), except for natural resource management groups (mostly water and forest user associations), for which only a third of the studies reported positive effects. More than two-thirds of the studies analysing self-help and women's groups reported improvement in incomes.

Among the services offered by FOs, marketing assistance for farm products and services that provide access to market information have the highest association with improvement in incomes (Fig. 3d). Extension and financial services also seem to play a positive role, but natural resource management services do not seem to translate into short-term improvement in incomes. Our data, however, do not indicate whether income gains are achieved through a combination of these services or whether a few services on their own have a large influence on improving incomes.

In the studies that quantified changes in income $(33$, or $14 \%)$, increases ranged widely from $3 \%$ to $70 \%$ over the studied period (often between 2 and 5 years). Out of our 239 studies, 7 (3\%) reported inconsistent income gains characterized by fluctuations over years and seasons. Such fluctuations were attributed to external and socio-demographic factors such as commodity prices, weather and climate impacts, crop and livestock losses caused by pests and diseases, varying product quality and insufficient family labour, or illness of household members ${ }^{26,27}$. However, 25 studies (10\%) mentioned that FOs assisted famers to stabilize their income through access to reliable markets, higher bargaining power with wholesalers and retailers, and more stable prices through access to consistent and reliable markets. This indicates that FOs have the ability to mitigate risks that cause fluctuations in the incomes of their members.

Production quality. After income gains, improved production quality was the next most commonly reported impact. Changes in production quality were typically measured in terms of improved quality of 


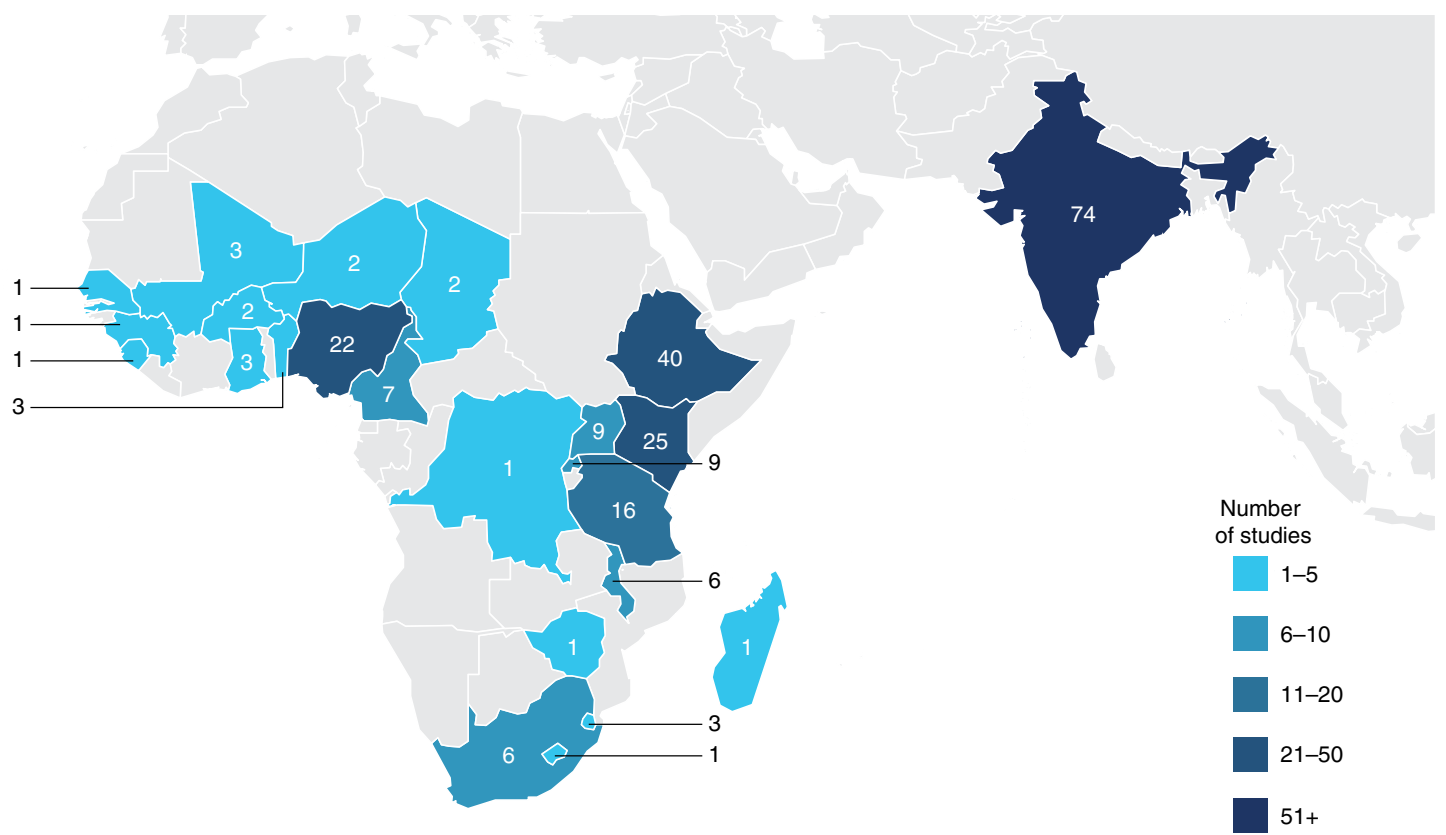

Fig. 1 | Studies included by country. The map shows the number of studies analysing FOs included in the review by country $(n=239)$ in each of the 24 countries considered.

crops, especially fruits and coffee, as well as dairy products. Positive contributions to production quality were reported in 48 studies (20\%) whereas no improvements in production quality could be identified in 13 studies (5\%). Positive impacts on production quality were mostly delivered by FOs engaged in crop production $(65 \%)$ and in FOs with no restriction on membership (79\%) (Fig. 3b).

With few exceptions, the share of studies that find positive impacts of FOs on production quality is similar across FO types. Studies analysing rural self-help and women's groups provide few accounts of production quality improvements and there seems to be no association between financial cooperatives and quality improvements (Fig. 3c).

The reported improvements in production quality are mostly driven by marketing information and output marketing services, as reported in around two-thirds of the studies (Fig. 3d). This mostly related to a switch to organic production, stronger connections with buyers and improved value chains, as found by Bezecon ${ }^{28}$. The provision of extension and input marketing services also seems to matter, as indicated in one-third of the studies, mostly focused on improved practices in the field, collection and storage. Other types of FO services seem to have a limited association with production quality improvements.

Yield changes. Typically, indicators to measure changes in yield include amount produced per hectare or per animal for livestock, volume of dairy products and reductions in crop losses. Positive contributions to yield were delivered in 46 studies (19\%), while no improvements in yield were listed in 27 studies (11\%). Positive impacts on yield were mostly delivered by FOs engaged in crop production (70\%) with no restriction on membership (87\%) (Fig. 3b).

Improvements in yield were mostly driven by producer groups, farmers' associations and agricultural cooperatives, for which approximately one-quarter of the studies reported yield improvements. Studies analysing other FO types reported yield improvements much less often or, in the case of financial cooperatives, did not report any improvements (Fig. 3c).

As in the case of impacts on incomes, output marketing services seem to matter the most for yield improvements. Extension services and access to market information are the other two services that are associated with higher yields (Fig. 3d). A greater capacity of producers to deploy sophisticated inputs and management practices, as a result mainly of FO extension services in combination with access to inputs, may have a strong effect on members' yield levels, as found in Chindi et al. ${ }^{29}$ and Wassie at al. ${ }^{30}$. Extension services provided by FOs have been shown to have positive impacts specifically on the use of fertilizers or high-quality and climate-resilient seeds ${ }^{31}$.

Environment. In 57 studies (24\%), there were documented improvements in environmental parameters mostly in terms of resilience-building such as flood protection, wetland management to promote nature-based solutions to climate change, water and land conservation practices to respond to climate change impacts, improved water quality and quantity and soil conditions, and reduced erosion. All these factors contribute to longer-term yield improvement, sustainable production and risk reduction, so they can be expected to have measurable long-term effects on farmer income (beyond the period of study).

However, 15 studies (6\%) mentioned no improvements or negative impacts on the environment, mostly relating to water pollution and land clearing. Positive impacts on the environment were mostly delivered by FOs engaged in crop production (53\%) with no restriction on membership (78\%) (Fig. 3b).

Unsurprisingly, positive environmental impacts are predominantly reported by studies focused on natural resource management FOs. Only a few studies concerned with FOs for economic support, such as agricultural and dairy cooperatives, report positive environmental impacts (Fig. 3c). However, it is possible that studies that focus on FOs oriented towards economic support do not measure environmental impacts. In these cases, any positive impacts in terms of income and yield may have actually resulted from sustainable practices such as improved soil and water management as well as adaptation responses to climate change impacts. The only substantial impacts were adaptation to climate change and resilience-building (11 studies, or 4.6\%) and implementation of organic farming methods (10 studies, or $4.2 \%$ ). There were also examples of engagement in forest and biodiversity management, 
a

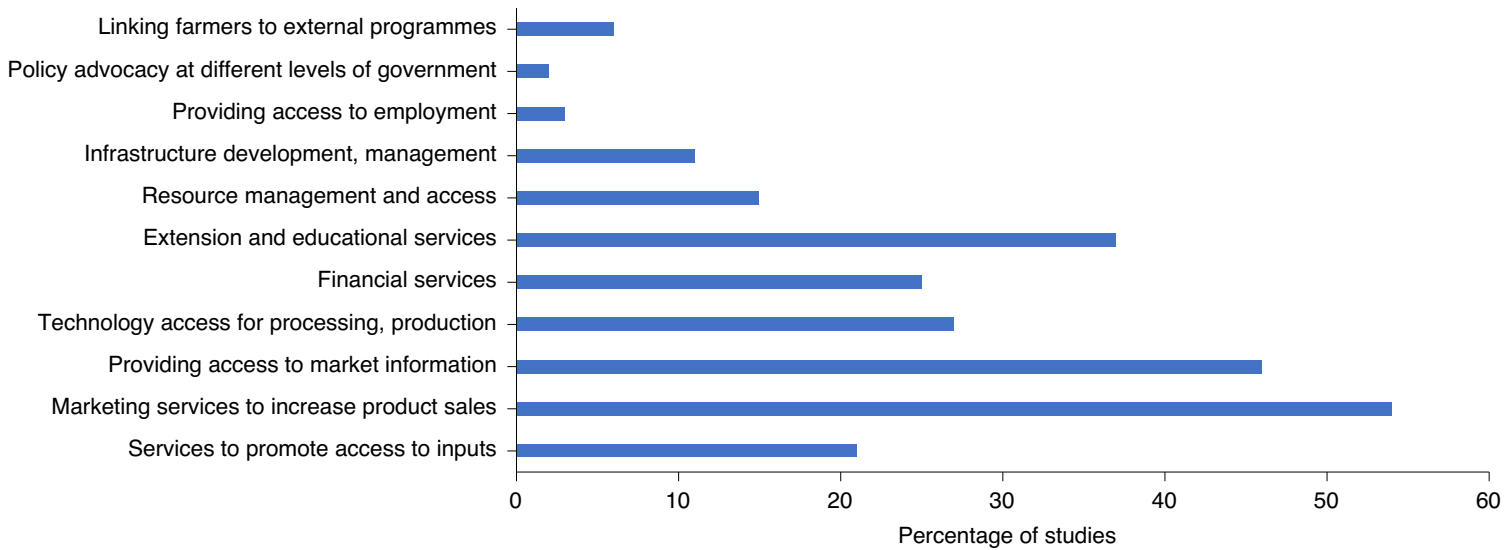

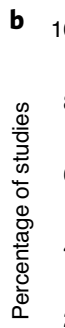
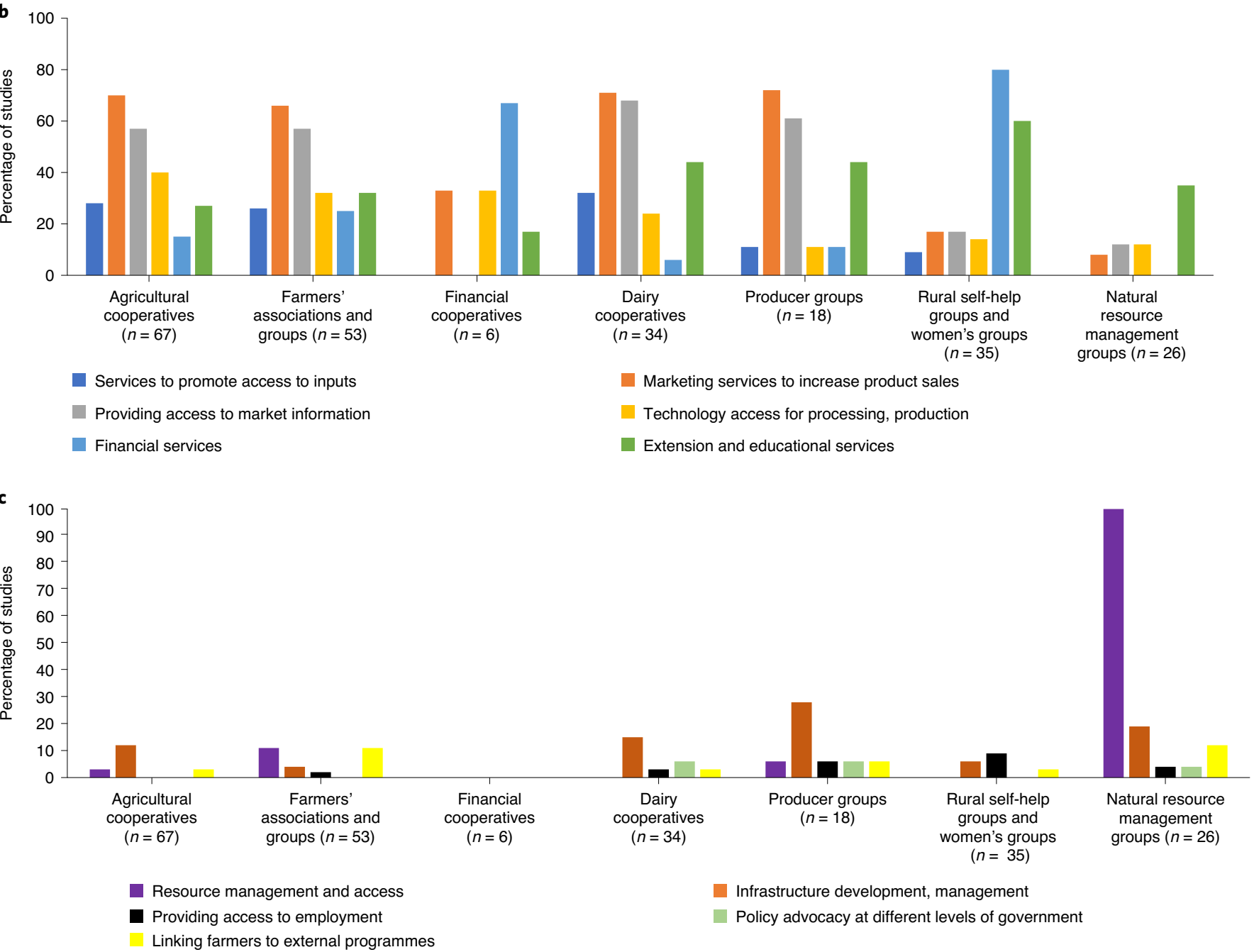

Fig. 2 | Services provided by FOs. a, Representation of services in the included studies ( $n=239$ ). Most of the studies reported the delivery of multiple services, thus the sum across all the services is above $100 \%$. b. Services with the highest representation in the studies by FO type. c, Services with the lowest representation in the studies by FO type. Most of the studies delivered multiple services, thus the sum across all the services is greater than $100 \%$. Financial cooperatives did not provide any of these services.

addressing water quality and availability and the use of renewable energy. These activities were motivated by production needs such as irrigation or energy for processing and storage (for example Bekele and $\mathrm{Ando}^{32}$ ) or as the outcome of particular government support campaigns to improve irrigation, for example ${ }^{33}$.
Environmental improvements were delivered by specific services targeting natural resource management (mostly water, forest and pasture) as well as outcomes of market information and output marketing (Fig. 3d). In addition, studies focusing on other types of FOs that deliver extension and marketing services also reported 
a
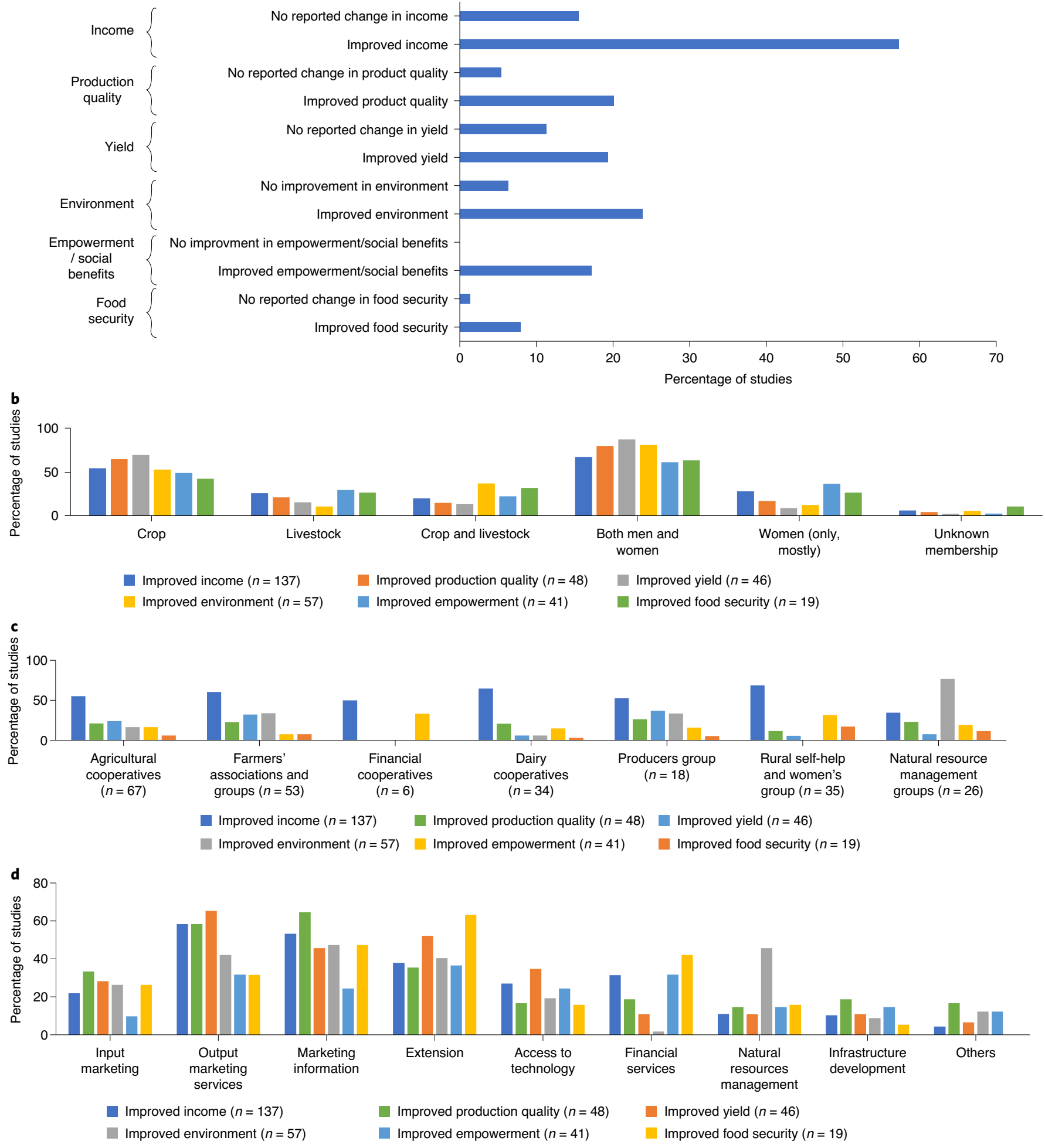

Fig. 3 | Impact of FOs. a, Proportions of studies reporting different types of impact (as percentage of studies in that category, $n=239$ ). $\mathbf{b}$, Positive impacts by type of production and membership in the studies. c, Positive impacts by FO type. d, Positive impacts by FO services. The sum of improvements and no improvements does not add up to $100 \%$ for each impact because not all the studies analysed the respective impacts. Most (59\%) of the studies delivered multiple impacts, thus the sum across all of the services is greater than $100 \%$.

environmental improvements, as some of the promoted management practices aimed at better yields (such as small-scale irrigation and targeted fertilizer application) were provided by FO extension services that in turn contribute to improved water quality and quantity $^{34}$. Management practices promoted by such FOs, aimed at improving yields and/or resource use efficiency (such as small-scale irrigation and targeted fertilizer application), were also found to contribute to improved water quality and quantity ${ }^{34}$.

For natural resource management groups, livelihoods were strengthened and made more resilient through improvements in the 
Natural resource management groups $(n=26)$ Rural self-help and women's cooperatives $(n=35)$

$$
\begin{array}{r}
\text { Producers groups }(n=18) \\
\text { Diary cooperatives }(n=34) \\
\text { Financial cooperatives }(n=6) \\
\text { Farmers' associations and groups }(n=53) \\
\text { Agricultural cooperatives }(n=67)
\end{array}
$$
Agricultural cooperatives $(n=67)$

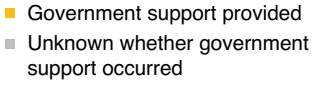

Fig. 4 | Government support to FOs. Bars indicate the proportion of each type of FO receiving support from national governments. In total, $40 \%$ of the reviewed studies reported some sort of support from national governments to FOs. Government support may include input and investment subsidies, conditional and unconditional cash transfers, infrastructure support programmes to develop roads, irrigation, storage facilities and others, non-targeted support to assist with start-up costs, government-financed extension services and tax exemptions on FO products.

quality or quantity of forest resources, irrigation water or pasture. More predictable and secure access to forest resources also provided a risk management strategy to deal with income fluctuation, as illustrated by Maretzki ${ }^{26}$, Ingabire et $\mathrm{al}^{27}$ and others.

Other impacts. Of the studies on self-help and women's groups-predominantly located in India-about 20\% reported improvements in food security and $31 \%$ in social empowerment. Natural resource management groups are the other type of FOs reporting such benefits, although present in very few studies. Empowerment was measured through self-reported increases in confidence and psychological well-being and participation in domestic decision-making, as well as improved business knowledge, leadership and management skills, and engagement in civic affairs. Approximately $20 \%$ of the studies mentioned the importance of higher income and access to credit to pay school fees, health care costs or to increase savings. The information on food security benefits is limited, with only 19 studies (8\%) addressing this parameter. These studies focused on assistance related to food access through income fluctuations as well as through increasing food availability due to extension support and access to inputs resulting in yield improvements.

Factors affecting FO service delivery. Studies were also assessed for their reporting of factors that could have mitigated or strengthened the impacts of the FOs' membership and service delivery. These were placed in two groups, concerned with external and socio-economic factors, as detailed below.

External factors. To assess the reported role of external factors on FO services, we first focused on support provided by national governments to FOs (Fig. 4). Of the studies reviewed, $40 \%$ reported that FOs received government support in the form of input and investment subsidies, conditional and unconditional cash transfers, infrastructure support programmes to develop roads, irrigation, storage facilities and others, non-targeted support to assist with start-up costs, government-financed extension services and tax exemptions on FO products. Besides government support, $25 \%$ of the reviewed studies mentioned support from local non-governmental organization (NGOs), international projects or donor initiatives. Across the various types of FO, the highest rate of government support was reported in studies of natural resource management groups (60\%), although a higher share of farmers' associations and groups received external support when NGOs were included.
Table 1 | Major types of socio-economic factor influencing the impacts of the FOs

\begin{tabular}{l}
$\begin{array}{l}\text { Factors and Observed effects } \\
\text { share of studies }\end{array}$ \\
\hline
\end{tabular}

Gender and Most of the FOs contribute to increasing male control gender relations over production and revenues. Men are more likely to (22; 9.2\%) purchase fertilizers and other inputs and have better access to credit. Predominantly male membership of FOs can be a barrier to female participation.

Access to land Members of FOs are likely to have larger land holdings and assets $(17 ; 17.1 \%)$ than other community members and possess at least a radio and some durable goods.

The poorest landholders with the smallest plots tend not to be members.

Education $\quad$ FO members tend to have attained primary education $(16 ; 6.7 \%) \quad$ or higher. Farmers with lower levels of education are less likely to be members of FOs.

Poverty Poorer farmers are less likely to participate in FOs (20; 8.4\%) due to limited financial resources to cover FO fees, purchase inputs and participate in $\mathrm{FO}$ decisions.

Distance to Farmers isolated from year-round roads are less likely markets to be members of FOs. The distance to markets is $(9 ; 3.8 \%)$ negatively correlated with membership.

The number of studies and the percentage of the total $(n=239)$ are shown in parentheses.

Other external factors beyond government or NGO support have been reported relating to climatic, weather and extreme events that affected production, changes in local administration and migration. From these three factors, climate variability and related effects were mentioned in 30 studies (12.6\%) because of their negative implications for production and yield. Local administration was listed in 17 studies (7.1\%) which typically stressed the importance of relationships with local governments to improve the ability of FOs to successfully deliver services.

Some of the reviewed studies identified specific recommendations for government policies to assist in service delivery and strengthen the impacts of FOs. The most common suggestion was to direct government support to FOs through extension services, access to credit and support for market access, as well as infrastructure investment (28 studies, $12 \%$ ); and strengthening natural resource management policies, mostly on water management and climate change adaptation (27 studies, 11\%).

Finally, our scoping review identified a small number of studies $(14$, or $6 \%)$ that referred to interactions with the private sector in terms of FOs' contracts with input companies, interactions with private-sector buyers, engagement in contract farming and private sector-driven extension provision.

Socio-economic factors. FO impacts can vary between members as households are highly heterogeneous in terms of their socio-economic characteristics and ability to take advantage of FO services. Sixty-eight of our studies identified factors influencing membership and service delivery (Table 1). These factors (which are inter-related) include gender and gender relations, access to land, education and poverty levels and remoteness/access to infrastructure. We also found four studies (1.7\%) that identified support to purchase inputs for production or access education for poor households ${ }^{21,35}$.

\section{Discussion}

As our scoping review shows, the literature on the impacts of FO membership on small-scale agricultural producers covers different 
types of FO in multiple countries of SSA and India. Positive impacts on farmers' income, yield and production were found, as well as some benefits for food security and the environment.

FO services and members' incomes. Our review revealed that FO services that enhance access to markets-for example, product marketing and market information-have positive impacts on member income as well as yield and product quality. This is consistent with the broader literature, which argues that the diverse services that FOs provide to connect small-scale producers to markets lead to positive impacts by assisting the individual members to overcome challenges such as low quantity or quality of products and frequent supply constraints, as well as by assisting with skill development and access to inputs ${ }^{22}$. In addition, access to financial services was shown in our findings to be critical to achieve improved income ${ }^{23}$. Member access to credit will be even more crucial for FOs to respond to future challenges such as climate change impacts and risk management, which require additional investments in climate-resilient crops, irrigation or insurance ${ }^{36}$.

Extension and educational services delivered by FOs have a substantial presence across all types of FOs in our review and delivered positive impacts. These services addressed skill, knowledge and information deficiencies that the members faced in relation to production decisions and practices. Types of services included information about input application, farming practices and production systems; market information; health and safety; and managerial and business skills-as well as knowledge about environmental stewardship and sustainability. These services would ideally be bundled flexibly and responsively to meet specific and dynamic local production constraints and market opportunities. In practice, however, providing these services to individual ssmall farmers is costly; collectives such as FOs make extension services more cost effective and feasible ${ }^{23}$. FOs can provide the institutional infrastructure for effective knowledge management, applied research and practical innovation to respond to diverse local production constraints or changing market conditions. Our results reinforce the value of extension services in the context of FOs and are consistent with literature findings that FO extension services benefit smallholders by improving financial literacy and the uptake of sustainable practices to achieve productivity and income gains ${ }^{36,37}$.

We infer from these results that policy development and programming should support FOs in the effective delivery of services that provide access to markets-both input and output-through targeted market information, infrastructure investment to improve market access mostly focused on road development, logistical support and extension to improve outcomes across different forms of FOs. Smallholders would probably benefit from FO provision of financial services such as consolidating and administering small-scale loans, seasonal input financing or crop insurance schemes based on measurable climate parameters (such as rainfall) rather than complex, case-by-case yield calculations. This set of multiple services for extension, infrastructure, market and financial services should be central to the design of FOs.

In terms of avenues for future research, our scoping review indicates that the benefits provided by a given FO may differ between individual members ${ }^{14,38}$. Although we found information comparing benefits for marginalized groups (as discussed below), this aspect of the analysis warrants further research. Similarly, further investigation of the positive spill-over effects ${ }^{39}$ of FOs on non-members and local communities would strengthen the case for FOs in supporting smallholder livelihoods.

Limited FO benefits for marginal producers. Reviewed studies mostly focused on those smallholder households with sufficient resources to benefit from engagement in FOs. Although the broader literature identifies several characteristics, such as farm size, gender of the household head, education and age, that influence FO membership and the heterogeneity of impacts ${ }^{40}$, our findings reveal that distance of households from markets is also an important variable hindering FO benefits. Gassner et al. $^{41}$ argue for differentiating among smallholders on the basis of the availability of resources. Households engaged in small-scale farming as a livelihood may have varying income and assets, resources to reinvest in agriculture or access to better-paid non-farm jobs to transition out of farming ${ }^{38}$. Those households that are on the margin and lack resources are likely to incur higher transaction costs to access FO services ${ }^{39}$ and thus need to be supported, while possible barriers and incentives need to be carefully revisited to make FOs more accessible ${ }^{42}$.

The gender of the household head was a prominent factor; studies suggest that benefits such as income, yield and production quality are lower for female-headed farm households ${ }^{40}$. FOs seem to be less effective for younger, less literate and female farmers, even if they become members. In addition, women (both married and unmarried) are often constrained in their ability to take advantage of FO services to improve crop yield, production systems and marketing. Some studies suggest that the homogeneity of women's self-help groups positively affected women's likelihood of joining, as a higher proportion of female members is more appealing to other women $^{43}$. In India, rural self-help groups and women's cooperatives show positive impacts on women's empowerment and access to credit, but often limited impact on domestic gender relations ${ }^{44}$.

Our results on gender, combined with our results on the other characteristics of marginalization (for example, distance to market) indicate that marginalized groups of farmers are less likely to participate in or to benefit from participation in FOs. This implies that policy development and programming in Africa and India should focus on the levers that induce them to more actively engage in FOs. Marginalized small-scale farmers may require different support systems to first improve their capacities, skills and resources as well as connections to infrastructure before they are able to benefit from FO membership. With regards to gender, policy development and programming should focus on improving the participation of women in FOs. One way is to mobilize women to form female-focused FOs and provide support through agricultural extension aimed at building the abilities of women farmers in areas such as production technology uptake and marketing ${ }^{45}$.

Limited food security benefits. This scoping review found a very low number of studies evaluating the contributions of FOs to food security compared with studies on improving income. This may also be due to our sample selection criteria, which may have resulted in studies that focused on non-marginalized small farmers for whom food security may not be a research outcome of interest.

Gains to food security attributable to FOs require additional research, as few previous studies examined this relationship. Although marginal, remote and socially disadvantaged households are the ones who typically suffer from food insecurity and who would gain most from FO participation, the studies show that marginalized producers are particularly difficult to engage in FOs for the reasons discussed above. It is also worth further studying food security impacts among more prosperous farmers, as improvements in indicators such as income or yield do not always translate into better food security or nutrition if, for example, households spend additional income on non-food items ${ }^{46}$.

We suggest that a distinction be made by policymakers between food security versus income or poverty reduction when prioritizing interventions in smallholder agriculture. For marginalized farmers who have limited capacity to benefit from FO membership, food security challenges require different interventions. Instead of improving production systems or market access, these might instead focus on, for example, basic social protections, income support, nutritional supplements or seasonal food security packs ${ }^{41}$. 
FO services and natural resource management. Natural resourcebased FOs were able to address soil erosion, improve water availability and contribute to reforestation and forest rehabilitation, thereby improving member resilience through access to higher-quality resources. These impacts were mostly achieved using targeted services to strengthen collective management of water, forest and pasture. The extensive work on common pool resources has demonstrated the ability of self-organized collectives to sustain key resources ${ }^{47}$ and our results align well with this body of work. Research more specific to FOs has shown, for example, that FOs designed for collective forest, water and pasture resource management in Africa and other parts of the world ${ }^{48,49}$ have resulted in positive impacts for members.

Some studies reported that climate change and weather events affected FO members' ability to produce and sell crops due to negative impacts on harvest and impacts on markets and related infrastructure. To promote sustainable agricultural practices and address climate risk, FOs should reassess whether input use, extension services, production technologies and resource management practices are consistent with sustainability and climate resilience criteria. This could lead to greater attention to sustainable production practices and more judicious natural resource management to preserve ecosystem function under increased climate stress. These additional complexities will challenge FOs to devote more resources to innovation but they will become increasingly important to ensure the sustainability of agricultural production systems and risk-adjusted returns to farmers ${ }^{50}$.

Our findings show that fluctuations in farmers' incomes in FOs is at least partly because of climate change-induced uncertainties, but at the same time we find that very few types of FO offer natural resource management services. The type of FOs that predominantly focus on natural resource management seem to be successful in delivering positive environmental impacts. The literature also suggests that other types of FO targeting the environment may improve yields, but not report on these services ${ }^{51}$. The implication of these findings for policy development and programming is that broader ecosystem and natural resource management should be more widely incorporated in the extension services of FOs to mitigate the risk induced by environmental degradation and climate change. This may require better documentation of current practices that contribute to the environment, as well as training and investment in innovation for FOs to demonstrate the benefits of new, more sustainable practices-so that they feel confident promoting such practices in agricultural systems.

Government role in supporting FOs. The literature shows that, on the one hand, governments play a substantial role in creating and supporting FOs. They can provide initial financial assistance ${ }^{15,16}$ as well as long-term support to increase asset levels that contribute to FOs' competitiveness and investment opportunities ${ }^{9}$. Moreover, government-subsidized FOs can become a buyer of last resort for farmers to sell their products, but often at lower prices than they would receive in a market ${ }^{52}$. Product price fluctuations were a substantial feature in many of the reviewed studies, so improved price stability was an important benefit of FO membership. Contrastingly, external support can also prop up weak and dysfunctional FOs and prolong inefficiencies ${ }^{53}$, with FO membership possibly representing a way of insulating small-scale producers from the hardships of essential structural change ${ }^{53}$.

Given the important role of governments in creating and supporting FOs, as well as the potential for political interference, the data extraction criteria used here identified available information on government and/or donor support for FOs, as well as cases where FOs do not provide the details of such support.

Final remarks. Our findings suggest generally positive evidence for the ability of FOs to provide important benefits to their members, and although only a minority of studies explicitly identify the role of government in the FOs that they study, this role was mostly a constructive one. There is abundant support in the broader literature ${ }^{23}$ for widespread participation in FOs; governments can be more proactive in supporting them by promoting legal frameworks for FO operation and providing access to credit and extension services to enable more widespread and effective engagement of small-scale farmers in FOs. Finally, while the contribution of government and support of NGOs can be substantial, the connections between this support and FO benefits has not been well documented in our sample of studies, indicating the need for additional research to explore the supporting role of governments and other entities in FO performance. Specific investigation of FO engagement in politics and policy, as well as the influence of governmental and other programmes on these FOs, would be beneficial to gain a fuller picture of FO contributions to members' livelihoods and environmental sustainability.

In addition to the government and NGO support to FOs, there is a growing interest in engagement with the private sector ${ }^{54}$. The number of studies assessing the impacts of such engagement was low in our review. Future research should focus on exploring whether the nature of supporting organization (government/NGO/ private players) makes much difference in the performance of FOs.

A final caveat is that the papers in our sample may be subject to publication bias, as studies reporting positive results concerning FO impacts are more likely to be published than studies reporting insignificant or negative results. Twenty-eight of the studies included in our review (12\%) provide accounts of no measurable improvement in FO members' livelihoods. However, we cannot rule out the possibility of a larger publication bias because of this preference for positive results ${ }^{55,56}$

\section{Methods}

Scoping review and protocol pre-registration. Scoping reviews do not seek to 'synthesize' evidence nor aggregate findings from different studies ${ }^{57,58}$, but rather provide a narrative or descriptive account of available research without focusing on the strength of evidence ${ }^{58}$. Other types of review that do require quality appraisal, such as systematic reviews, often include a lower number of studies than scoping reviews ${ }^{57}$. The outcomes of scoping reviews can include policy and practice recommendations and suggestions for areas of study that are not currently well addressed in the literature.

This scoping review was prepared following guidelines from the Preferred Reporting Items for Systematic Reviews and Meta-Analyses extension for scoping reviews (PRISMA-ScR) ${ }^{59}$. This approach comprises five steps: (1) identifying the research question (that is, "what are the services that farmer organizations provide to members, and what impacts do those services have on small-scale producers' livelihoods and the environment?"); (2) identifying relevant studies using pre-determined definitions (see Box 1); (3) study selection; (4) extracting and charting the data; and (5) collating, summarizing and reporting the results.

Databases, search methods and citation management. A search strategy was developed and tested by the authors to identify all available publications pertaining to the research question. Search terms included variations of the key concepts in the research question (that is FOs and the geographic regions of interest). Searches included the following electronic databases: CAB Abstracts and Global Health (accessed via Web of Science); Web of Science Core Collection (accessed via Web of Science); and Scopus (accessed via Elsevier). Full search strategies used for each database, including grey literature, can be accessed in their entirety at https://osf. io/4gt $3 \mathrm{~b} /$.

In addition to scholarly literature, the authors also conducted a comprehensive search of grey literature using custom web-scraping scripts. The authors tested search strings on each website before initiating web-scraping. An existing Google Chrome extension was needed to scrape dynamically generated websites. The authors combined and removed duplicated results from the databases and the grey literature searches using a Python script.

Eligibility criteria. A total of 239 studies were included in the review on the basis of the following inclusion criteria: (1) explicit reference to small-scale farmers, small-scale producers or smallholders; (2) explicit reference to farmer organizations, as defined in the protocol (https://osf.io/4gt3b/); (3) explicit reference to SSA, individual SSA countries or India; (4) published after the year 2000; (5) explicit reference to the impacts of FOs on livelihoods, including food security, income or the environment; (6) focus on agricultural production (crop or animal) for human and animal consumption; (7) no focus on stallholder 
activities in forestry, agroforestry, fisheries and aquaculture; (8) use of primary and secondary data to demonstrate contribution to outcomes; (9) published in English or French. The PRISMA flow diagram summarizes the study selection process and indicates the number of articles excluded at each phase of screening (Supplementary Fig. 1.6). The data extraction template (available in the Supplementary Information) documented the study type and various aspects of FOs and their membership.

Study selection. Studies were selected following a three-stage process. The first stage involved title screening, a process where the main elements of each study are reviewed, such as the PICo components (participants, intervention and comparator, but not outcomes) that can help identify the corpus of relevant studies $^{60}$. Title screening helped to considerably reduce the workload of citation screening while maintaining high recall of relevant studies ${ }^{60}$. In this study, manual title screening was enhanced by machine learning to accelerate the process. The machine learning model provided additional metadata about each study, including the identification of a study population and study geography. The additional metadata accelerated the speed with which title screening could be conducted. The second stage consisted of uploading the remaining articles to Covidence, a systematic review software package that performs title and abstract screening to exclude articles that did not meet the inclusion criteria. Two independent authors reviewed each title and abstract, and a third independent author resolved discrepancies. In the third stage, a single reviewer performed full-text screening of papers that met all inclusion criteria and those whose eligibility could not be established during title and abstract screening. Supplementary Fig. 1.6 presents the study selection process and indicates the number of articles excluded at each phase of screening. Some of the papers presented multiple studies such as ref. ${ }^{61}$ covering two studies from Ethiopia, ref. ${ }^{62}$ covering studies from Kenya and Uganda, ref. ${ }^{63}$ covering India and Ethiopia, ref. ${ }^{64}$ covering two studies from Kenya and ref. ${ }^{65}$ covering two studies from India. Thus, the number of studies that this review refers to $(n=239)$ exceeds the number of papers $(N=234)$ included in the review. In addition, some of the included studies used aggregated household data that did not allow us to clearly separate FOs of the same type and that, in some cases, operate in adjacent locations and/or belonged to the same umbrella organization. Because the studies often discuss services and impacts across the multiple FOs, we were not able to clearly separate these FOs in the studies; this could have led to underreporting of the total number of FOs that have been studied in the individual papers.

Data extraction and analysis. A data extraction template for scoping reviews originally developed in ref. ${ }^{66}$ was adapted for this scoping review. The data extraction template is available in Supplementary Data 1. Extracted data included all basic citation information and each study's location, design and methodology. We also extracted data about FOs in the studies, including their type and cost of membership, number of years in operation and focal activities of crops and livestock. These indicators were selected because of their reported potential influence on achieving impacts in the literature ${ }^{9,52,64}$. We also collected information about the services FOs provide to members, including marketing services, output marketing, market information, financial services, technology services such as education, extension, research, skills, technology access, infrastructure development and management, managing common property resources and others.

The impacts of FOs were separated into categories, detailing impacts of FOs services on livelihoods, agricultural production and the environment. As stated in Box 1, livelihood impacts include changes in income and food security. We also collected impacts that are often reported on the literature on FOs' impacts such as improvements in yield, production quality and empowerment ${ }^{67-69}$.

Given that SDG target 2.4 concerns the linkages between agricultural production and the environment, information about the impacts of FOs on the environment was also collected. The environmental impacts were identified as the outcomes of services primarily aimed at improving the benefits to members such as income, yield or production quality (for example through access to irrigation, improved grazing land or reduced impacts of climate change on production). Environmental impacts included resilience-building and responses to climate change such as flood protection and changes in water quality and quantity, soil characteristics and erosion, land in production/set aside, biodiversity, the use of renewable energy sources/reduced used of fossil fuel-based energy and others. To specify the impacts, we also collected any quantification noted in the studies such as percentage change in income, change in yield and production quality, percentage of change in land use and others. Similarly, we documented the presence or lack thereof any external and socio-demographic factors that could potentially influence the impacts of FO services.

The data extraction also included an assessment of the quality of the methodology used in each of the included papers. We examined whether sampling methods were clearly specified and whether the sampling strategy for both qualitative and quantitative studies were suitable-in particular, if the sample selection was based on specific criteria to select the FOs' members and non-members of the FOs and if these criteria were explicitly listed in the study.
Next, the studies were reviewed for their methodology justification based on the studies' research design, focusing on two criteria: if the methodology used control groups and/or conducted pre- and post- assessments when assessing the FOs' benefits to the members. Finally, we assessed whether a clear description of the method and methods used for data analysis and its appropriateness to make sure reported FO's benefits to the members are based on data collected from the sample instead of for example based on literature. Based on these criteria, studies lacking clearly-stated methodological approaches and/or deemed inadequate were classified as low quality (Supplementary Table 1.1).

We synthesized data on FO services and their impacts on livelihood and the environment in the context of documented external and socio-demographic factors. Contextual details on the basic characteristics of FOs included in the studies, such as their geographical location, years of operation, membership type and fees can be found in Supplementary Figs. 1.3 and 1.4.

\section{Data availability}

All data are available from the corresponding author on reasonable request.

\section{Code availability}

The scripts used for literature screening/selection and data analysis are available on request from the corresponding author. The protocol for this study was registered on the Open Science Framework before study selection, and can be accessed at https://osf.io/cxrwb/.

Received: 22 March 2020; Accepted: 11 September 2020; Published online: 12 October 2020

\section{References}

1. Sustainable Development Goal 2 (Sustainable Development Knowledge Platform, UN, 2017); https://sustainabledevelopment.un.org/sdg2

2. Ricciardia, V., Ramankuttya, N., Mehrabia, Z., Jarvisa, L. \& Chookolingoa, B. How much of the world's food do smallholders produce? Glob. Food Secur. 17, 64-72 (2018).

3. The State of Food and Agriculture 2014: Innovation in Family Farming (FAO, 2014).

4. Bacon, C. M. et al. Explaining the 'hungry farmer paradox': smallholders and fair trade cooperatives navigate seasonality and change in Nicaragua's corn and coffee markets. Glob. Environ. Change 25, 133-149 (2014).

5. Habtemariam, L. T. \& Kassa, J. G. \& Gandorfer, M.Impact of climate change on farms in smallholder farming systems: yield impacts, economic implications and distributional effects. Agric. Syst. 152, 58-66 (2017).

6. IPCC: Summary for Policymakers. In Climate Change and Land: An IPCC Special Report on Climate Change, Desertification, Land Degradation, Sustainable Land Management, Food Security, and Greenhouse Gas Fluxes in Terrestrial Ecosystems (eds Shukla, P. R. et al) (IPCC, in the press).

7. Thorp, R., Stewart, F. \& Heyer, A. When and how far is group formation a route out of chronic poverty? World Dev. 33, 907-920 (2005).

8. Ifejika, S. C., Kiteme, B., Wiesmann, U. \& Jörin, J. Community-based water development projects, their effectiveness, and options for improvement: lessons from Laikipia, Kenya. Afr. Geogr. Rev. 37, 192-208 (2016).

9. Markelova, H. \& Mwangi, E. Collective action for smallholder market access: evidence and implications for. Afr. Rev. Policy Res. 27, 621-640 (2010)

10. Sumelius, J. et al. Cooperatives As a Tool For Poverty Reduction and Promoting Business In Tanzania Discussion Paper No. 65 (Univ. Helsinki, 2013).

11. Okumu, B. \& Muchapondwa, E. Welfare and Environmental Impact of Incentive Based Conservation: Evidence from Kenyan Community Forest Associations Working Paper No. 706 (Economic Research Southern Africa, 2017).

12. Gugerty, M. K., Biscaye, P. \& Anderson, C. L. Delivering development? Evidence on self-help groups as development intermediaries in South Asia and Africa. Dev. Policy Rev. 37, 129-151 (2018).

13. Malawi Poverty Reduction Strategy Paper (Government of Malawi, 2002); https://www.imf.org/External/NP/prsp/2002/mwi/01/043002.pdf

14. Bijman, J. \& Wijers, G. Exploring the inclusiveness of producer cooperatives. Curr. Opin. Environ. Sustain. 41, 74-79 (2019).

15. Shiferaw, B., Hellin, J. \& Muricho, G. Improving market access and agricultural productivity growth in Africa: what role for producer organizations and collective action institutions? Food Secur. 3, 475-489 (2011)

16. Chirwa, E. W. \& Kydd, J. G. Study on Farmer Organizations in Smallholder Tea in Malawi (Imperial College, 2005).

17. Francesconi, G. N. \& Wouterse, F. Building the managerial capital of agricultural cooperatives in Africa. Ann. Public Coop. Econ. 90, 141-159 (2019). 
18. Hussi, P., Murphy, J., Lindberg, O. \& Brenneman, L. The Development of Cooperatives and Other Rural Organizations: The Role of the World Bank Technical Paper. No. WTP 199 (World Bank, 1993).

19. Okem, A. E. \& Nene, M. N. An examination of the success factors of cooperative-run agricultural schemes: a case study of Intlantsi Agricultural Secondary Co-operative Limited. Int. J. Sust. Dev. World. 7, 112-120 (2014)

20. Luviene, N., Stitely, A. \& Hoyt, L. Sustainable Economic Democracy: Worker Cooperatives for the 21st Century (Community Innovators Lab, MIT, 2010).

21. Chagwiza, C., Muradian, R. \& Ruben, R. Cooperative membership and dairy performance among smallholders in Ethiopia. Food Policy 56 165-173 (2016).

22. Bernard, T., Taffesse, A. S. \& Gabre-Madhin, E. Impact of cooperatives on smallholders' commercialization behavior: evidence from Ethiopia. Agric. Econ. 39, 147-161 (2008).

23. Gramzow, A., Batt, P. J., Afari-Sefa, V., Petrick, M. \& Roothaert, R. Linking smallholder vegetable producers to markets: a comparison of a vegetable producer group and a contract-farming arrangement in the Lushoto District of Tanzania. J. Rural Stud. 63, 168-179 (2018).

24. Trebbin, A. \& Hassler, M. Farmers' producer companies in India: a new concept for collective action. Environ. Plan. 44, 411-427 (2012).

25. Boadu, F. O. Cooperatives in Sub-Saharan Africa: Agricultural Law and Economics in Sub-Saharan Africa (Academic, 2016).

26. Maretzki, A. N. Women's NutriBusiness cooperatives in Kenya: an integrated strategy for sustaining rural livelihoods. J Nutr. Educ. Behav. 6, 327-334 (2007).

27. Ingabire, C. et al. Towards commercial agriculture in Rwanda: understanding the determinants of market participation among smallholder bean farmers. Afr. J. Food Agric. Nutr. Dev. 17, 12492-12508 (2017).

28. Bezencon, V. Producers and the fair trade distribution systems: what are the benefits and problems. Sustain. Dev. 19, 60-70 (2011).

29. Chindi, A. et al. Participatory potato seed production: a breakthrough for food security and income generation in the central highlands of Ethiopia. Open Agric. 2, 205-212 (2017).

30. Wassie, S. B., Kusakari, H. \& Masahiro, S. Inclusiveness and effectiveness of agricultural cooperatives: recent evidence from Ethiopia. Int. J. Soc. Econ. 46, 614-630 (2019).

31. Deshmukh, A. R., Deokar, D. K., Jadhav, S. S. \& Nimase, R. G. Study of present working, financial position, business turn-over and business gain (profit/loss) of dairy co-operation societies of Raigad district. Asian J. Anim. Sci. 4, 226-230 (2009)

32. Bekele, T. \& Ango, T. G. Do interventions from participatory action research improve livelihood and reduce conflicts over forest resources? A case study from south central Ethiopia. Small-Scale For. 14, 441-458 (2015).

33. Mojo, D., Fischer, C. \& Degefa, T. Collective action and aspirations: the impact of cooperatives on Ethiopian coffee farmers' aspirations. Ann. Public Coop. Econ. 87, 217-238 (2016).

34. Dirwai, T. L., Senzanje, A. \& Mudhara, M. Water governance impacts on water adequacy in smallholder irrigation schemes in KwaZulu-Natal province, South Africa. Water Policy 21, 127-146 (2019).

35. Mutonyi, S. The effect of collective action on smallholder income and asset holdings in Kenya. World Dev. Perspect. 14, 100099 (2019).

36. Wossen, T. et al. Impacts of extension access and cooperative membership on technology adoption and household welfare. J. Rural Stud. 54, 223-233 (2017).

37. Mogues, T., Morris, M., Freinkman, L., Adubi, A. \& Ehui, S. in Public Expenditures for Agricultural and Rural Development in Africa (eds Mogues, T. \& Benin, S.) 68-108 (Routledge, 2012).

38. Dorward, A. Integrating contested aspirations, processes and policy: development as hanging in, stepping up and stepping out. Dev. Policy Rev. 27, 131-146 (2009).

39. Bernard, T. \& Spielman, D. J. Reaching the rural poor through rural producer organizations? A study of agricultural marketing cooperatives in Ethiopia. Food Policy 34, 60-69 (2009).

40. Abate, G. T., Francesconi, G. N. \& Getnet, K. Impact of agricultural cooperatives on smallholders' technical efficiency: empirical evidence from Ethiopia. Ann. Public Coop. Econ. 85, 257-286 (2014).

41. Gassner, A. et al. Poverty eradication and food security through agriculture in Africa? Rethinking objectives and entry points. Outlook Agric. 48, 309-315 (2019).

42. Minah, M. \& Carletti, A. M. P. Mechanisms of inclusion: evidence from Zambia's farmer organisations. Euro. J. Dev. Res. 31, 1318-1340 (2019).

43. Dohmwirth, C. \& Hanisch, M. Women and collective action: lessons from the Indian dairy cooperative sector. Commun. Dev. J. 53, 675-693 (2018).

44. Sangeetha, V., Bahal, R., Singh, P. \& Venkatesh, P. Impact of NGO-led self-help groups on the empowerment of rural women-experiences from South India. Outlook Agric. 42, 59-63 (2013).

45. Meier zu Selhausen, F. What determines women's participation in collective action? Evidence from a western Ugandan coffee cooperative. Fem. Econ. 22, 130-157 (2016).
46. Javdani, M. Malawi's agricultural input subsidy: study of a Green Revolution-style strategy for food security. Int. J. Agric. Sustain. 10, 150-163 (2012).

47. Ostrom, E. Governing the Commons: The Evolution of Institutions for Collective Action (Cambridge Univ. Press, 1990).

48. Aarnoudse, E., Closas, A. \& Lefore, N. Water User Associations: A Review of Approaches and Alternative Management Options for Sub-Saharan Africa No. 615-2019-850 (IWMI, 2018).

49. Fratkin, E. \& Mearns, R. Sustainability and pastoral livelihoods: lessons from East African Maasai and Mongolia. Hum. Organ. 62, 112-122 (2003)

50. Lutz, C. \& Tadesse, G. African farmers' market organizations and global value chains: competitiveness versus inclusiveness. Rev. Soc. Econ. 75, 318-338 (2017)

51. Fayet, L. \& Vermeulen, W. J. Supporting smallholders to access sustainable supply chains: lessons from the Indian cotton supply chain. Sustain. Dev. 22, 289-310 (2014)

52. Ojermark, P. \& Chabala, C. The Development of Independent Cooperatives in Zambia: A Case Study (FAO,1994).

53. Nilsson, J. Organisational principles for co-operative firms. Scand. J. Manag. 17, 329-356 (2001)

54. Daum, T. \& Birner, R. Agricultural mechanization in Africa: myths, realities and an emerging research agenda. Glob. Food Secur. https://doi.org/10.1016/ j.gfs.2020.100393 (2020).

55. Ton, G., Vellema, W., Desiere, S., Weituschat, S. \& D’Haese, M. Contract farming for improving smallholder incomes: what can we learn from effectiveness studies. World Dev. 4, 46-64 (2018).

56. Brodeur, A., Lé, M., Sangnier, M. \& Zylberberg, Y. Star Wars: the empirics strike back. Am. Econ. J. Appl. Econ. 8, 1-32 (2016).

57. Arksey, H. \& O'Malley, L. Scoping studies: towards a methodological framework. Int. J. Soc. Res. Methodol. 8, 19-32 (2005).

58. Levac, D., Colquhoun, H. \& O’Brien, K. K. Scoping studies: advancing the methodology. Implement. Sci. 5, 69 (2010).

59. Tricco, A. C. et al. PRISMA extension for scoping reviews (PRISMA-ScR): checklist and explanation. Ann. Intern. Med. 169, 467-473 (2018)

60. Rathbone, J. et al. Expediting citation screening using PICo-based title-only screening for identifying studies in scoping searches and rapid reviews. Syst. Rev. 6, 233 (2017).

61. Francesconi, G. N. Cooperation for Competition: Linking Ethiopian Farmers to Markets (Wageningen Univ., 2009); https://edepot.wur.nl/122089

62. Ombogoh, D. B., Tanui, J., McMullin, S., Muriuki, J. \& Mowo, J. Enhancing adaptation to climate variability in the East African highlands: a case for fostering collective action among smallholder farmers in Kenya and Uganda. Clim. Dev. 10, 61-72 (2016)

63. Gender and Governance in Rural Services: Insights from India, Ghana, and Ethiopia (World Bank \& IFPR, 2010); http://agris.fao.org/agris-search/search. do? recordID $=$ US2014606530

64. Sibelet, N. \& Montzieux, M. Resilience factors in the coffee secto of Kenya: from food security to product removal. Cah. Agric. 21, 179-191 (2012)

65. Kurien, V. India's Milk Revolution: Investing in Rural Producer Organizations (World Bank, 2007); http://documents.worldbank.org/curated/ en/748851468771700148/ Indias-milk-revolution-investing-in-rural-producer-organizations

66. Barrett, C., Ghezzi-Kopel, K., Hoddinott, J., Tennant, E. \& Upton, J. The state of the literature on individual and household resilience: a scoping review. Open Science Framework https://doi.org/10.17605/ osf.io/5rgb7 (2019)

67. Grashuis, J. \& Su, Y. A review of the empirical literature on farmer cooperatives: performance, ownership and governance, finance, and member attitude. Ann. Public Coop. Econ. 90, 77-102 (2019).

68. Tefera, D. A., Bijman, J. \& Slingerland, M. Agricultural co-operatives in Ethiopia: evolution, functions and impact. J. Int. Dev. 29, 431-453 (2017).

69. Durach, C. F., Kurpjuweit, S. \& Wagner, S. M. The impact of additive manufacturing on supply chains. Int. J. Phys. Distrib. Logist. Manag. 47, 954-971 (2017).

\section{Acknowledgements}

We thank the Federal Ministry of Economic Cooperation (BMZ Germany) and the Bill \& Melinda Gates Foundation for funding under the project Ceres2030: Sustainable Solutions to End Hunger.

\section{Author contributions}

K.G.-K. and J.K. led the search process, contributed to title screening and writing. L.B. liaised with M.M., R.M.R.T., M.H., A.C.C. and B.T. on the search process, coordinated the paper screening, contributed to screening at all stages, developed 
the data extraction template and contributed to data extraction, data analysis and writing. E.N. and L.T. identified the overall research question and contributed to article screening at the abstract stage and writing. R.M.R.T., C.I.S., E.N. and M.K. supplied specific aspects of cooperatives in Africa and India and FOs focused on natural resource management expertise, and contributed to writing. L.B., M.M. and R.M.R.T. led the data analysis and the policy recommendations.

\section{Competing interests}

The authors declare no competing interests.

\section{Additional information}

Supplementary information is available for this paper at https://doi.org/10.1038/ s43016-020-00164-X.

Correspondence and requests for materials should be addressed to L.B.
Reprints and permissions information is available at www.nature.com/reprints.

Publisher's note Springer Nature remains neutral with regard to jurisdictional claims in published maps and institutional affiliations.

(c) Open Access This article is licensed under a Creative Commons

Attribution 4.0 International License, which permits use, sharing, adaptation, distribution and reproduction in any medium or format, as long as you give appropriate credit to the original author(s) and the source, provide a link to the Creative Commons license, and indicate if changes were made. The images or other third party material in this article are included in the article's Creative Commons license, unless indicated otherwise in a credit line to the material. If material is not included in the article's Creative Commons license and your intended use is not permitted by statutory regulation or exceeds the permitted use, you will need to obtain permission directly from the copyright holder. To view a copy of this license, visit http://creativecommons. org/licenses/by/4.0/.

(C) The Author(s) 2020 